\title{
PULMONARY HYALINE MEMBRANES, ASPIRATION AND PNEUMONIA
}

\author{
BY \\ T. WADE-EVANS \\ From the Departments of Pathology and Obstetrics, University of Manchester
}

(RECEIVED FOR PUBLICATION AUGUST 25, 1960)

The structures now called hyaline membranes were first described in the lungs of the newborn baby by Hoccheim (1903), and were considered by him to be aspirated vernix caseosa. At present there is little evidence that hyaline membranes arise as a direct result of aspiration, although aspirated substances may be included within them; many conflicting views of their pathogenesis have been held, but opinion is now in favour of their origin within the lung itself, from material, probably protein, lost through the local capillaries. Until fibrin was identified within the membranes the exact mechanism by which they developed remained uncertain, for it was difficult to understand how they could te formed from soluble serum proteins, unless these were in the process grossly denatured. A rational explanation of the formation of membranes became possible, however, after the demonstration with fluorescent antibody of their fibrin content (Gitlin and Craig, 1956); further studies using orthodox histological methods confirmed the observations of these workers and showed that the membranes arose as a result of incomplete resorption of fibrin-containing oedema fluid, and suggested that fibrin was indeed their essential component.

An important conclusion drawn from this finding is that the membranes found in the lungs of newborn babies do not differ structurally from those of older patients, in whom membranes may form in a variety of diseases. In all of these there is a temporary increase in capillary permeability which is great enough to allow the escape of fibrinogen as well as of other plasma proteins; the conditions include not only inflammatory lesions and neoplastic or other infiltrations of the lung itself, but also cardiovascular disturbances, in particular severe left ventricular failure, with or without uraemia. Membrane formation in these cases is merely one common end result of a number of different pathological processes, and the possibility that this may be so in the lung of the newborn must be considered.

In older children and adults membrane formation sometimes complicates pneumonia (Farber and Wilson, 1932). In the newborn these two processes are often found together; the relation between the two conditions is often, however, difficult to determine. Before the past decade hyaline membranes in the newborn were most frequently discussed in papers concerned primarily with pneumonia; although at that time origin of the membranes from vernix was generally accepted, Steinharter (1937) recognized structures in the newborn which he considered to differ from 'vernix membranes' and to be the result of pneumonia. Potter (1952) believed pneumonia was an important complication in many babies with hyaline membranes, particularly in those who died after the end of the second day. More recently the concept of the membranes forming as the result of a specific pathological process or 'hyaline membrane disease' has been widely held, so that less attention has been paid to the possibility of their origin in other ways.

In this paper cases are presented in which membrane formation in the lungs of the newborn is secondary to pneumonia, and an attempt is made to define histological criteria for the recognition of such membranes; the observations recorded show that in about one-fifth of all cases in which membranes are present they are the result of an inflammatory process. The membranes found in other babies, in whom their origin is independent of pneumonia, are, to distinguish them, referred to as 'primary' hyaline membranes.

\section{Material}

During the 10 years 1949-1958 autopsies were performed at St. Mary's Hospitals, Manchester, on 800 babies dying in the neonatal period, histological material being available from 791; of these, 727 $(91.9 \%)$ died in the first week of life. The cases described below were discovered during a review of sections taken from the lungs of these babies, and they include many in which diagnosis was difficult. Membranous structures were found in 
175 of the lungs, 143 being of the type defined above as 'primary'. The remaining 32 cases are discussed in this report; they are presented in three groups in the order in which my attention was drawn to them.

\section{Group I: Hyaline Membranes and Aspiration}

In this group membranes are seen where there has been gross soiling of the lung by aspirated material. Epithelial squames from the liquor amnii are seen in the lungs of many of the babies who die in utero or soon after birth; when present in small numbers these are probably without significance, but when numerous they are usually held to indicate prenatal anoxia, showing an increased aspiration of amniotic fluid as a result of increased intrauterine respiratory movements. The squames seen in these circumstances are separate, dispersed and readily drawn into the finest air spaces, although they may there become concentrated and packed into small groups by the absorption of amniotic fluid. Sometimes, however, squames are present in a more coarsely particulate material, e.g. meconium, vernix caseosa or mucus from the respiratory tract, and this may plug bronchi or bronchioles, causing atelectasis or obstructive emphysema (Emery, 1956). In the series reviewed, widespread aspiration of such material had occurred in 25 cases, and in six of these there were also eosinophil membranes; their presence recalls the original theory of formation of hyaline membranes from vernix caseosa, and might in the past have been held to support it. The existence of structures of this type was recognized by Gruenwald $(1953,1958)$ who suggested that hyaline membranes might be of different sorts and that true 'vernix membranes' were found in a small number of more mature babies.

The first case is typical of the group.

Case 1. A 23-year-old primigravid patient, 43 weeks pregnant, was delivered by caesarean section because of foetal distress; eight hours after the onset of labour the membranes ruptured spontaneously with drainage of heavily meconium-stained fluid, and foetal bradycardia was noted. The baby (birth weight: $2.85 \mathrm{~kg}$.; crownheel length: $55 \mathrm{~cm}$.) was asphyxiated at birth, but after meconium had been removed from the respiratory tract began at three minutes to breath regularly. Slight cyanosis persisted, however, with occasional apnoeic attacks, the baby's condition deteriorating shortly before death at 36 hours. At autopsy, the significant findings were in the respiratory system; the lungs were expanded and heavy (right: 58 g., left: $46 \mathrm{~g}$.; heart: $25 \mathrm{~g}$.), with irregular areas of aeration alternating with wedge-shaped areas of dull red-purple colour in all lobes. The bronchi contained dark green mucoid material.

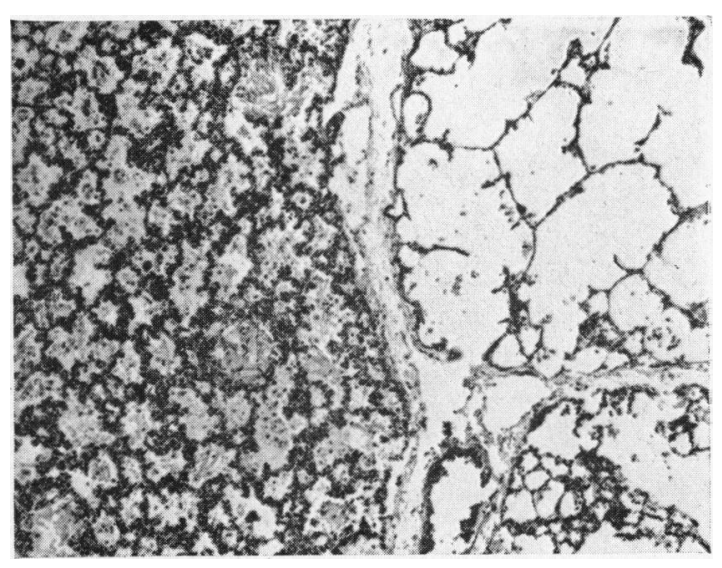

FIG. 1.-Case 1: the variation in pattern between adjacent aerated and unaerated lobules is seen. (H. and E. $\times$ 48.)

On histological examination, there was a striking variation in pattern between neighbouring secondary lobules (Fig. 1). Many were aerated; some indeed were overdistended; others were not, but retained the pattern of the foetal lung, the lumina of the air spaces being either narrow or slightly distended, containing fluid in which there were moderate numbers of polymorphonuclear leucocytes mixed intimately with squames. The lungs appeared mature; there was little mesenchyme between the terminal air spaces and, while individual cuboidal lining cells persisted, they were not numerous; the form and distribution of the surviving cuboidal cells was identical in both aerated and non-aerated lobules. Many small bronchi and bronchioles were obstructed by a mixture of wisps of mucus and clusters of anucleate squames; a few rounded masses of mucus with a little granular yellow pigment were also present.

Eosinophil membranes were seen in a number of the unaerated lobules (Fig. 2), but not elsewhere. They

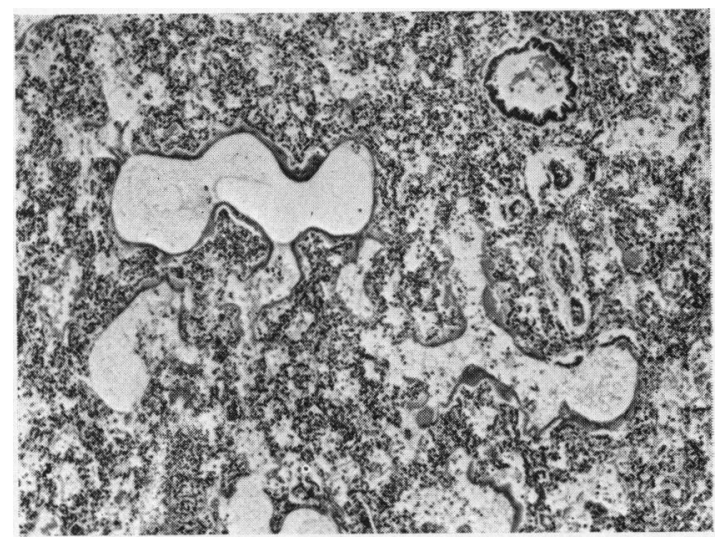

FIG. 2.-Case 1: examples of the membranous structures seen in some of the unaerated lobules. (H. and E. $\times 48$.) 


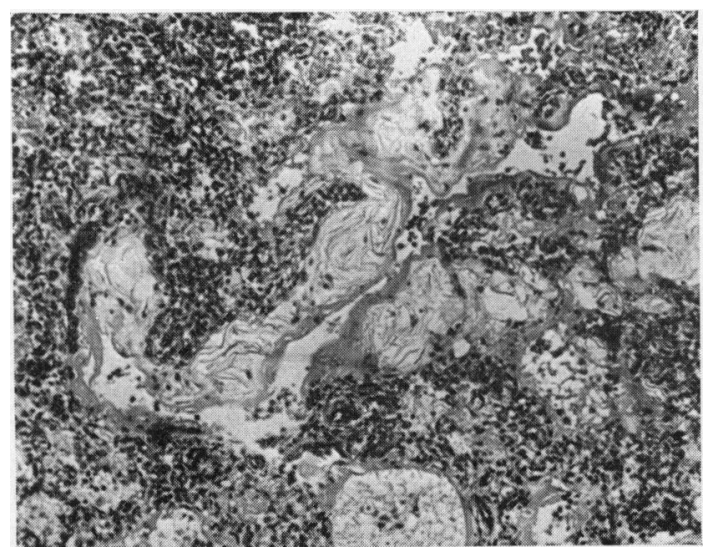

Fig. 3.-Case 1: eosinophil material identical with that forming the membranes lies in close association with the aspirated material, but is proximal to it. (H. and E. $\times$ 96.)

were usually thick and formed a complete lining for the enclosing air space, often extending into the terminal bronchioles. In places they lay close to masses of aspirated material and were proximal to it (Fig. 3). This association was not constant, however; indeed, the membranes were seen only in those areas in which there was pneumonia, and in places appeared to be in direct continuity with the exudate (Fig. 4). Strands of eosinophil material were sometimes seen adjacent to the meconium blocking the bronchi, but only where there were also leucocytes. The membranes themselves contained small numbers of polymorphs that were well preserved, their appearance contrasting with that of the pyknotic or fragmented round nuclei sometimes seen in primary hyaline membranes. The exudate was in general of the diffuse type seen in congenital or intrapartum pneumonia, although there were also a few foci of more recent origin, which lay proximal to the membranes and which contained larger numbers of polymorphs with many coarse strands of fibrin; these strands were haematoxyphil and also gave the Feulgen reaction. In some places oedema fluid had collected proximal to the membranes and contained small numbers of polymorphs.

\section{Comment}

The gross and microscopical appearances of the lungs in the other cases of this group were similar and the features of all six are summarized in Table 1. It will be noted that in five meconium was found at autopsy in the bronchi or had contaminated the amniotic fluid. In all of them the lungs showed alternating massés of bright pink aerated and of dull red-purple airless tissue which appeared to be secondary lobules as they were wedge-shaped and were separated on the pleural surfaces and in the sub-pleural regions by connective tissue septa. In five this pattern of alteration was seen throughout,

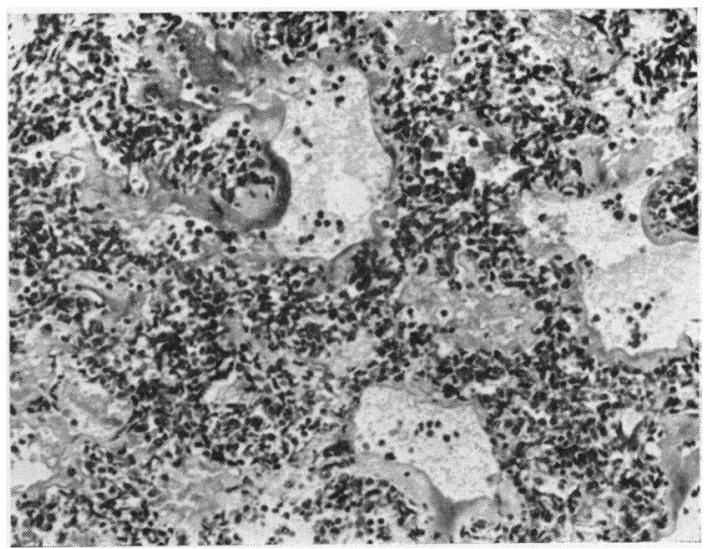

Fig. 4.-Case 1: the membranes are continuous with exudate seen in the more peripheral air-spaces. (H. and E. $\times$ 130.)

while in the sixth aeration was confined to the right upper lobe. The aerated lobules often appeared overdistended, as if there had been incomplete obstruction of the supplying bronchioles; three cases were complicated by interstitial emphysema, one of them with pneumothorax.

The membranes in these cases differed in several ways from those commonly seen in premature infants with respiratory distress. Their distribution was patchy, rather than widespread and even throughout the lungs; they occurred in babies who, where the air passages were not obstructed, were able to expand and aerate their lungs normally; the lungs were not immature and the pattern attributed to 'resorption collapse' (Potter, 1952) was not seen. Certain differences in structure have been emphasized in the description of Case 1 ; the membranes where present were usually thick, formed a complete lining for the air-spaces in which they lay, and not infrequently extended to line the terminal bronchioles; they often contained apparently healthy leucocytes, rather than the pyknotic or fragmented epithelial nuclei included in primary hyaline membranes.

While the occurrence of membranes in these cases suggested that the eosinophil as well as the particulate material had been aspirated, this was not so. Membranes or similar eosinophil material were found only where there was an inflammatory reaction, in some fields lying in continuity with the exudate; they were found in none of the 19 other cases examined in which there was widespread aspiration of mucus or meconium with little accompanying pneumonia; it seemed obvious that they were formed by the action of respiration on such exudate, either by the initial expansion of the containing 
lung at birth, or by the continued pressure of inspired air after this time.

The nature of the pneumonia was less certain. It was apparently not due to the chemical irritation of the aspirated substances, for these could lie in the lung without reaction, in some cases for nearly two days, in parts adjacent to those in which there was exudation and membrane formation. It was more likely to be the result of infection, although no organisms were seen in the sections, and culture was negative in the two cases in which it was attempted: these babies had, however, been given antibiotics. Estimation of the time at which infection occurred was difficult. In places the exudate was similar in character to that seen in the 'congenital' pneumonia of infants who are stillborn or who die soon after birth; in these the terminal air spaces are slightly distended, usually regularly and with preservation of the 'crumpled' pattern of the unaerated foetal lung, and the exudate contains small or moderate numbers of leucocytes mixed intimately with squames or scraps of mucus, with but little detectable fibrin. It is less easy to interpret this type of reaction in babies who survive for longer times, although when it is found in those dying at any time in the first day it can be assumed that the pneumonia in these cases too has arisen before birth. In the group of cases under discussion assessment was made difficult by the survival of most into the second day, and by the presence in many of fresh focal pneumonia. Aspiration must, however, have occurred during labour, or at the latest soon after birth, and the close association of the exudate with the aspirated material suggested that the pneumonia had commenced at the same time, and that at least in some of the cases it was of intrapartum origin.

\section{Group II: Membrane Formation in Diffuse Pneumonia}

To investigate this further, a search was made for membrane formation in babies who had died within a few days of birth, and whose lungs showed diffuse pneumonia without evidence of aspiration, other than that of the commonly seen dispersed squames; in addition, a series of lungs containing hyaline membranes was reviewed for the presence of diffuse pneumonia. Eighteen cases of membrane formation in diffuse pneumonia were found, and

TABLE 1

DETAILS OF CASES IN GROUP I

\begin{tabular}{|c|c|c|c|c|c|c|c|c|}
\hline \multirow[b]{2}{*}{ Case } & \multirow[b]{2}{*}{ Sex } & \multirow{2}{*}{$\begin{array}{c}\text { Birth } \\
\text { Weight } \\
\text { (kg.) }\end{array}$} & \multirow{2}{*}{$\begin{array}{l}\text { Crown-heel } \\
\text { Length } \\
\text { (cm.) }\end{array}$} & \multirow[b]{2}{*}{$\underset{\text { (wks) }}{\text { Maturity }}$} & \multirow[b]{2}{*}{$\begin{array}{c}\text { Age } \\
\text { (hrs) }\end{array}$} & \multicolumn{2}{|c|}{ Maternal } & \multirow[b]{2}{*}{ Other Features } \\
\hline & & & & & & $\begin{array}{c}\text { Age } \\
\text { (yrs) }\end{array}$ & Parity* & \\
\hline 1 & $\mathbf{M}$ & $2 \cdot 89$ & 55 & 43 & 36 & 23 & 1 & $\begin{array}{l}\text { Caesarean section for foetal distress; liquor meconium } \\
\text { stained; regular respiration established at } 3 \text { minutes, but } \\
\text { later apnoeic attacks } \\
\text { Autopsy: lungs aerated but heavy with dull red-purple } \\
\text { wedge-shaped areas; green mucoid material in bronchi }\end{array}$ \\
\hline 2 & $\mathbf{M}$ & $2 \cdot 78$ & 50 & 40 & 31 & 23 & 1 & $\begin{array}{l}\text { Pregnancy and early labour normal; vertex delivery with } \\
\text { cord wound around neck; baby gasped intermittently for } \\
45 \text { minutes before regular respiration commenced } \\
\text { Autopsy: lungs heavy (Rt. } 46 \mathrm{~g} \text {., Lt. } 53 \mathrm{~g} \text {.) and similar in } \\
\text { appearance to those of Case } 1 \text {; small tentorial tear }\end{array}$ \\
\hline 3 & $\mathbf{M}$ & $3 \cdot 03$ & 53 & 42 & 18 & 37 & 1 & $\begin{array}{l}\text { Admitted after rupture of membranes, draining meconium- } \\
\text { stained liquor; normal vertex delivery } 12 \text { hours later; } \\
\text { much meconium aspirated from air-passages } \\
\text { Autopsy: lungs showed a similar pattern with, in addition, } \\
\text { interstitial emphysema (Rt. } 45 \text { g., Lt. } 37 \mathrm{~g} \text {.) }\end{array}$ \\
\hline 4 & $\mathbf{F}$ & $2 \cdot 72$ & 53 & 42 & 32 & 32 & 1 & $\begin{array}{l}\text { Normal labour with vertex delivery; baby breathed at } \\
\text { once, but much mucus removed from air passages; } \\
\text { remained cyanosed with rapid respiratory rate } \\
\text { Autopsy: interstitial emphysema of lungs and mediastinum } \\
\text { without pneumothorax; bronchi contained meconium; } \\
\text { alternating areas of aeration and 'atelectasis' }\end{array}$ \\
\hline 5 & $\mathbf{F}$ & $2 \cdot 82$ & 52 & 42 & 12 & 19 & 1 & $\begin{array}{l}\text { Short normal labour; membranes ruptured a little before } \\
\text { birth; liquor heavily meconium stained; respiration began } \\
\text { soon after birth, but was rapid and grunting } \\
\text { Autopsy: interstitial emphysema with left pneumothorax; } \\
\text { alternating areas of aeration and 'collapse' noted; left } \\
\text { tentorial tear }\end{array}$ \\
\hline 6 & $\mathbf{F}$ & $3 \cdot 60$ & 55 & 40 & 38 & 25 & 2 & $\begin{array}{l}\text { Short normal labour; much meconium removed from } \\
\text { respiratory tract; respiration rapid with persistent cyanosis } \\
\text { Autopsy: lungs heavy and dull purple throughout (Rt. } \\
\mathbf{4 0} \mathrm{g} \text {., Lt. } 32 \mathrm{~g} \text {.) with aeration of right upper lobe only }\end{array}$ \\
\hline
\end{tabular}

* After the birth of the baby examined. 
TABLE 2

DETAILS OF CASES IN GROUP II

\begin{tabular}{|c|c|c|c|c|c|c|c|c|}
\hline \multirow[b]{2}{*}{ Case } & \multirow[b]{2}{*}{ Sex } & \multirow{2}{*}{$\begin{array}{l}\text { Birth } \\
\text { Weight } \\
\text { (kg.) }\end{array}$} & \multirow{2}{*}{$\begin{array}{l}\text { Crown-heel } \\
\text { Length } \\
\text { (cm.) }\end{array}$} & \multirow[b]{2}{*}{$\underset{\text { (wks) }}{\text { Maturity }}$} & \multirow[b]{2}{*}{$\begin{array}{c}\text { Age } \\
\text { (hrs) }\end{array}$} & \multicolumn{2}{|c|}{ Maternal } & \multirow[b]{2}{*}{ Other Features } \\
\hline & & & & & & $\begin{array}{l}\text { Age } \\
\text { (yrs) }\end{array}$ & Parity* & \\
\hline 7 & $\mathbf{M}$ & $2 \cdot 07$ & 48 & 42 & 12 & 23 & 3 & $\begin{array}{l}\text { Medical induction two weeks after expected date of delivery; } \\
\text { short normal labour with late rupture of membranes } \\
\text { Autopsy: lungs heavy (Rt. } 30 \mathrm{~g} ., \mathrm{Lt} .22 \mathrm{~g} .) \text {, uniformly deep } \\
\text { purple and unaerated; no other significant finding }\end{array}$ \\
\hline 8 & $\mathbf{M}$ & $2 \cdot 75$ & 48 & 32 & 9 & 30 & 5 & $\begin{array}{l}\text { Maternal mitral stenosis; membranes ruptured spon- } \\
\text { taneously five days before onset of labour } \\
\text { Autopsy: tentorial tear and subdural haemorrhage; lungs } \\
\text { similar to above (Rt. } 33 \mathrm{~g} ., \text { Lt. } 28 \mathrm{~g} \text {.) }\end{array}$ \\
\hline 9 & $\mathbf{M}$ & $1 \cdot 75$ & 43 & 32 & 12 & - & 2 & $\begin{array}{l}\text { Spontaneous premature labour; district delivery; other } \\
\text { details unknown } \\
\text { Autopsy: lungs heavy and airless (Rt. } 27 \text { g., Lt. } 22 \text { g.); } \\
\text { no other significant finding }\end{array}$ \\
\hline 10 & $\mathbf{M}$ & 0.85 & 33 & 27 & 2 & 33 & 4 & $\begin{array}{l}\text { Spontaneous onset of premature labour three days after } \\
\text { membranes had ruptured; normal vertex delivery } \\
\text { Autopsy: 'atelectasis' (Rt. lung } 11 \text { g., Lt. } 9 \text { g.) }\end{array}$ \\
\hline 11 & $\mathbf{F}$ & $1 \cdot 51$ & 42 & 32 & 25 & 36 & 1 & $\begin{array}{l}\text { Surgical induction of labour using Queen Charlotte's } \\
\text { Hospital bag three days before delivery; maternal pre- } \\
\text { eclamptic toxaemia; vertex delivery } \\
\text { Autopsy: intraventricular haemorrhage extending into } \\
\text { subarachnoid space; lungs heavy and airless (Rt. } 20 \mathrm{~g} \text {, } \\
\text { Lt. } 16 \mathrm{g.)}\end{array}$ \\
\hline 12 & $\mathbf{M}$ & $1 \cdot 30$ & 38 & 28 & 1 & 25 & 1 & $\begin{array}{l}\text { Leaking amniotic fluid for six weeks before delivery; fluid } \\
\text { bloodstained for three days; pre-eclamptic toxaemia; } \\
\text { breech delivery } \\
\text { Autopsy: subarachnoid haemorrhage; lungs heavy (Rt. } \\
\text { 31 g., Lt. } 24 \mathrm{g.)}\end{array}$ \\
\hline 13 & $\mathbf{M}$ & $2 \cdot 45$ & 50 & 36 & $5 \cdot 5$ & 25 & 1 & $\begin{array}{l}\text { Surgical induction of labour for pre-eclampsia, by artificial } \\
\text { rupture of membranes; normal vertex delivery } 52 \text { hours } \\
\text { later; breathed soon after birth but severe apnoeic attack } \\
\text { at } 1 \text { hour } \\
\text { Autopsy: lungs 'atelectatic' (Rt. } 12 \mathrm{g.,} \text { Lt. } 10 \mathrm{~g} .) \text {; no } \\
\text { other important finding }\end{array}$ \\
\hline 14 & $\mathbf{M}$ & $0 \cdot 75$ & 33 & 26 & 4 & 35 & 1 & $\begin{array}{l}\text { Twin pregnancy: first twin; spontaneous rupture of mem- } \\
\text { branes two days before onset of labour; breech delivery } \\
\text { Autopsy: tentorial tear and subdural haemorrhage; lungs } \\
\text { 'atelectatic' (Rt. } 10 \mathrm{~g} ., \text { Lt. } 9 \mathrm{~g} .)\end{array}$ \\
\hline 15 & $\mathbf{F}$ & $1 \cdot 13$ & 38 & 32 & 8 & 28 & & $\begin{array}{l}\text { Twin pregnancy: second twin; membranes ruptured for } \\
\text { seven days; breech delivery; first twin stillborn } \\
\text { Autopsy: 'atelectasis' (Rt. } 12 \text { g., Lt. } 10 \mathrm{~g} .)\end{array}$ \\
\hline 16 & $\mathbf{M}$ & $3 \cdot 7$ & 55 & 40 & 12 & 23 & 4 & $\begin{array}{l}\text { Membranes ruptured spontaneously } 38 \text { hours before onset } \\
\text { of labour; normal vertex delivery; regular respirations } \\
\text { after seven minutes, but cyanosed with rib retraction; } \\
\text { later apnoeic attacks } \\
\text { Autopsy: haemorrhage into left cerebral hemisphere; lungs } \\
\text { appeared aerated (Rt. } 36 \mathrm{g.}, \text { Lt. } 31 \mathrm{~g} .)\end{array}$ \\
\hline 17 & $\mathbf{F}$ & $1 \cdot 81$ & 44 & 32 & 3 & 19 & 2 & $\begin{array}{l}\text { Spontaneous premature rupture of membranes two days } \\
\text { before normal delivery; irregular respiration from birth, } \\
\text { with apnoeic attacks } \\
\text { Autopsy: lungs showed infrequent areas of aeration } \\
\text { (Rt. } 32 \text { g., Lt. } 25 \text { g.); no other significant findings }\end{array}$ \\
\hline 18 & $\mathbf{F}$ & $1 \cdot 44$ & 41 & 33 & 7 & 23 & 2 & $\begin{array}{l}\text { Born before arrival; vertex delivery, but other details } \\
\text { unknown } \\
\text { Autopsy: bilateral tentorial tears with subdural haemor- } \\
\text { rhage; lungs airless (Rt. } 12 \text { g., Lt. } 9 \mathrm{~g} .)\end{array}$ \\
\hline 19 & $\mathbf{F}$ & 0.93 & 37 & 28 & 9 & 26 & 2 & $\begin{array}{l}\text { Spontaneous onset of premature labour; vertex delivery } \\
\text { after late rupture of membranes; baby gasped at birth } \\
\text { but respiration not established for nine minutes } \\
\text { Autopsy: intraventricular haemorrhage; lungs airless } \\
\text { (Rt. } 20 \text { g., Lt. } 15 \text { g.) }\end{array}$ \\
\hline 20 & $\mathbf{F}$ & $1 \cdot 67$ & 32 & 39 & $31 \cdot 5$ & 25 & 2 & $\begin{array}{l}\text { Paracentesis amnii five days before normal vertex delivery; } \\
\text { haemolytic disease; exchange transfusion not performed } \\
\text { Autopsy: lungs expanded but not aerated (Rt. } 32 \mathrm{~g} ., \text { Lt. } 22 \mathrm{~g} .)\end{array}$ \\
\hline 21 & $\mathbf{F}$ & $3 \cdot 51$ & 51 & 37 & 6 & 29 & 7 & $\begin{array}{l}\text { Spontaneous onset of labour with late rupture of mem- } \\
\text { branes; paracentesis amnii had been performed six weeks } \\
\text { before; haemolytic disease; vertex delivery; exchange } \\
\text { transfusion begun at one hour; collapsed and died at } \\
6 \text { hours } \\
\text { Autopsy: haemoperitoneum; lungs airless (Rt. } 27 \text { g., Lt. } 22 \text { g.) }\end{array}$ \\
\hline
\end{tabular}


TABLE 2 (continued)

\begin{tabular}{|c|c|c|c|c|c|c|c|c|}
\hline \multirow[b]{2}{*}{ Case } & \multirow[b]{2}{*}{ Sex } & \multirow{2}{*}{$\begin{array}{c}\text { Birth } \\
\text { Weight } \\
\text { (kg.) }\end{array}$} & \multirow{2}{*}{$\begin{array}{c}\text { Crown- } \\
\text { heel } \\
\text { length } \\
\text { (cm.) }\end{array}$} & \multirow[b]{2}{*}{$\begin{array}{c}\text { Maturity } \\
\text { (wks) }\end{array}$} & \multirow[b]{2}{*}{$\begin{array}{c}\text { Age } \\
\text { (hrs) }\end{array}$} & \multicolumn{2}{|c|}{ Maternal } & \multirow[b]{2}{*}{ Other Features } \\
\hline & & & & & & $\begin{array}{c}\text { Age } \\
\text { (yrs) }\end{array}$ & Parity* & \\
\hline 22 & $\mathbf{M}$ & $1 \cdot 26$ & 38 & 32 & 36 & 22 & 3 & $\begin{array}{l}\text { Spontaneous rupture of membranes five days before } \\
\text { delivery; vertex delivery; cried well at birth and breathed } \\
\text { regularly; sudden collapse at } 33 \text { hours } \\
\text { Autopsy: lungs dull purple and airless (Rt. } 18 \mathrm{~g} ., \text { Lt. } 14 \mathrm{~g} .) \text {; } \\
\text { no other significant finding }\end{array}$ \\
\hline 23 & $\mathbf{M}$ & $1 \cdot 81$ & 43 & 32 & 13 & 26 & 4 & $\begin{array}{l}\text { Spontaneous onset of labour with late rupture of mem- } \\
\text { branes; haemolytic disease with severe anaemia; given } \\
\text { digoxin and exchange transfusion attempted, but col- } \\
\text { lapsed and died } \\
\text { Autopsy: lungs airless, with a little fibrinous exudate on } \\
\text { pleura (Rt. } 29 \text { g., Lt. } 23 \text { g.) }\end{array}$ \\
\hline 24 & $\mathbf{F}$ & $2 \cdot 0$ & 43 & 37 & 24 & 24 & 1 & $\begin{array}{l}\text { Membranes ruptured before admission with pre-eclamptic } \\
\text { toxaemia; forceps delivery } 39 \text { hours later; baby cried } \\
\text { well after birth but had cyanotic attacks at } 1 \frac{1}{2} \text { and } 4 \frac{1}{2} \\
\text { hours, then persistent cyanosis } \\
\text { Autopsy: intraventricular and subarachnoid haemorrhage; } \\
\text { lungs dull purple and airless (Rt. } 25 \mathrm{~g} \text {., Lt. } 20 \mathrm{~g} \text {.) }\end{array}$ \\
\hline
\end{tabular}

* After the birth of the baby examined.

their pathological features are illustrated by the following examples. The histories and post-mortem findings are summarized in Table 2.

Case 7. A 23-year-old woman had previously had two normal deliveries at term. In her third pregnancy labour was induced medically at 43 weeks; it started promptly and was of short duration, with the normal vertex delivery of a male child. The membranes were intact until the beginning of the second stage (Stage I: two hours 10 minutes; II: 15 minutes; III: 10 minutes). The baby weighed $2.07 \mathrm{~kg}$., being thus by the accepted convention premature, but it was of wizened appearance, and seemed in other ways mature; the crown-heel length was $48 \mathrm{~cm}$. and ossification centres were present in the lower femoral epiphysis and talus. Observations on the placenta were unfortunately not recorded, but the mother was neither toxaemic nor hypertensive. At autopsy, the lungs were expanded, but not aerated, were dark in colour and relatively heavy (right: $30 \mathrm{~g}$., left: $23 \mathrm{~g}$.;

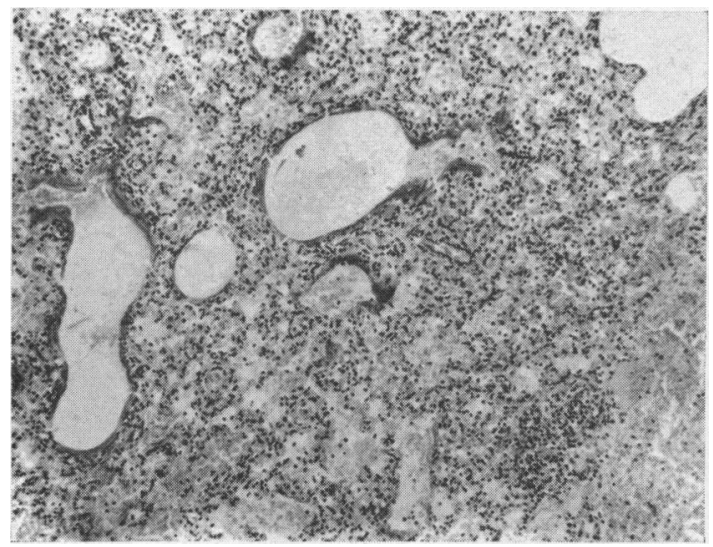

Fig. 5.-Case 7: membranous structures in a lung with diffuse pneumonia. (H. and E. $\times 69$.) heart, 17 g.). No other lesions of importance were found.

On histological examination, in spite of the low birth weight, the lungs appeared mature. There was little aeration although here and there the terminal bronchioles, with the spaces immediately beyond them, were rounded, some appearing empty and others containing oedema fluid (Fig. 5). The more distal air spaces, while retaining the foetal pattern, were regularly expanded, and they contained moderate numbers of polymorphonuclear leucocytes, which were mixed with amniotic squames and surrounded by granular eosinophil material; in this it was not possible to demonstrate fibrin. Diffuse haemorrhage had occurred into a few lobules. In places there was denser exudate with coarse strands or masses of fibrin, some of which showed an ill-defined patchy basophilia and gave the Feulgen reaction. Membranous structures were seen in much of the tissue, but their distribution was not regular. Some were eosinophil and of fibrillary or granular

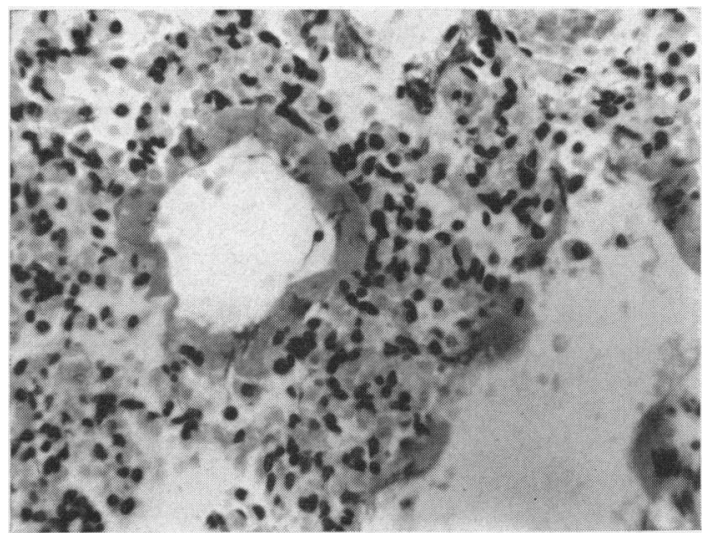

Fig. 6.-Case 7: eosinophil membranes which more closely resemble the 'primary' hyaline membranes seen in babies with respiratory distress. (H. and E. $\times 254$. 


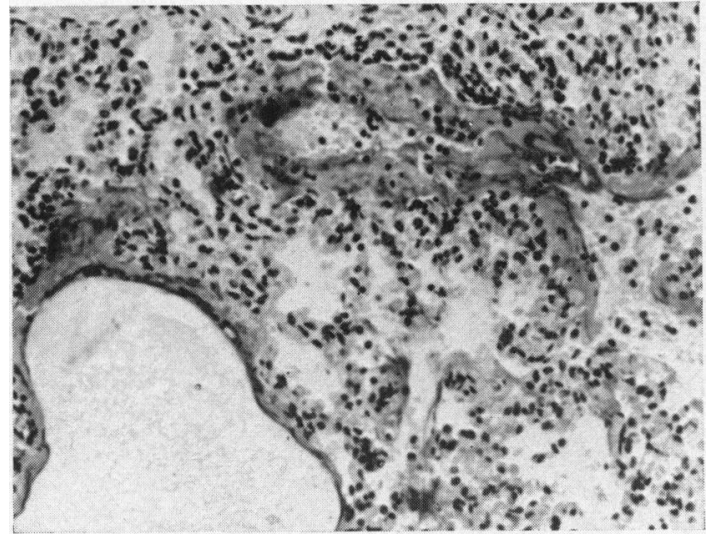

FIG. 7.-Case 7: some of the membranes (left) have ill-defined basophil areas which resemble those seen in the exudate (upper right). (H. and E. $\times$ 158.)

texture, without other feature, and as such were identical with primary hyaline membranes (Fig. 6). Others were less well formed, being of open texture with ill-defined surface; they were often incomplete or ragged, forming masses on the free margins of the alveolar or saccular septa, as if the lung tissue peripheral to them had been expanded since their formation. In a few places the membranes were thicker, more complete and similar in structure to the dense exudate described above, with ill-defined basophilia and Feulgen staining (Fig. 7).

Case 8. Labour started in a 30-year-old woman five days after spontaneous premature rupture of the membranes. She had mitral stenosis, but had previously had three normal deliveries at term without ill effect. Labour was short (Stage I: two hours 50 minutes; II: 10 minutes; III: 15 minutes), with normal delivery of a male child. Although the maturity given by the mother's history was 32 weeks, he weighed $2 \cdot 77 \mathrm{~kg}$. and

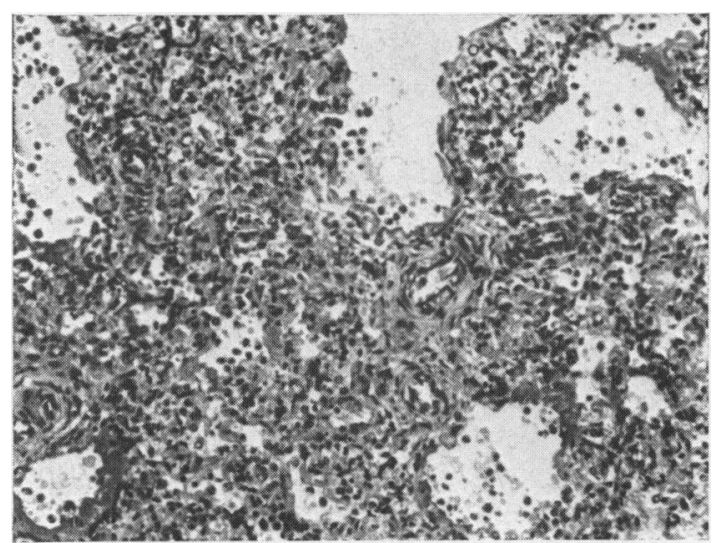

FIG. 8.-Case 8: ragged eosinophil membranes forming in a lung with diffuse pneumonia. (H. and E. $\times 137$. the crown-heel length was $48 \mathrm{~cm}$.; the siblings had weighed between 3.0 and $3.5 \mathrm{~kg}$. at term. The baby was slow to breath and had apnoeic attacks at $2 \frac{1}{2}$ and 7 hours, with a third, from which he did not recover. at 9 hours. Autopsy showed a right tentorial tear with subdural haemorrhage; the lungs were expanded and heavy, but not obviously aerated (right, $33 \mathrm{~g}$., left $28 \mathrm{~g}$.; heart $17 \mathrm{~g}$.).

On histological examination, the lungs appeared less mature than in the previous case, although the birth weight was greater. Here, too, the pattern was uniform, without aeration, other than of occasional bronchioles or alveolar ducts, but with regular expansion of the distal spaces, which contained polymorphs and squames, and, in places, denser exudate similar in character to that seen in Case 7. Membrane formation was patchy, being commonest where pneumonia was most marked; some membranes showed the staining reactions of the exudate and others were more uniformly eosinophil, if with ragged surface (Fig. 8).

\section{Comment}

The assessment of diffuse pneumonia of this type is not easy; it most commonly arises in utero as the result of aspiration of infected liquor amnii, although to distinguish between the presence in the lung of such fluid and an inflammatory reaction to it is often difficult. The importance of the pneumonia is uncertain, although it is probably not often the sole cause of death; it is usually of low grade, so that it may not harm an unhandicapped baby, being often seen at autopsy either in those who have suffered intrauterine anoxia, or in those who have died as the result of separate more severe lesions, and who presumably would have survived the infection alone. The difficulty of estimating the time at which this type of pneumonia begins has been discussed already; in the cases in this group it seems likely that the process had begun intrapartum, for all but three died in the first day, some within a few hours of birth, the lungs remaining for the greater part of foetal pattern, and the distribution of the exudate being characteristically diffuse.

In cases with such pneumonia, as was shown by Langley and Smith (1959) in stillbirths and neonatal deaths taken from the same autopsy series as was drawn on here, there was an increased incidence of inflammation of the foetal surface of the placenta, and of prolonged rupture of the membranes before delivery. It is of interest to note that in nine of the 16 cases in which adequate details of the obstetric history were available there was prolonged rupture of the membranes, and that in three others there had been recent surgical interference with the uterus, in two surgical induction of labour two and 
a half days before, and in the other paracentesis amnii five days before birth.

The membranes in these cases were often difficult to distinguish from primary hyaline membranes, and at times the two might indeed appear identical. Differentiation can often be made on the structural features of the pneumonic membranes, and by their patchy distribution; while the causative pneumonia is diffuse, it shows irregular accentuations, and the membranes are seen where these are most marked. There may be ill-defined basophil areas of the type illustrated, a feature rare in the absence of inflammation. The membranes may be laminated and may, like those seen in Group I, line the bronchioles as well as the respiratory part of the lung. Their ragged or incomplete appearance contrasts with that of fully-formed primary hyaline membranes, as does the expansion of the lung tissue distal to them.

However, it may not always be possible to make this distinction. If the inflammatory reaction in an intrapartum pneumonia continues when respiration is established after birth, with further exudation, the process becomes identical with that by which primary hyaline membranes are formed from fibrin escaping through the pulmonary capillaries; in the latter, also, small numbers of polymorphs may be present. In addition, primary hyaline membrane formation may be complicated by pneumonia, and, while this is often focal and intense, there is sometimes a more diffuse spread, both central to the membranes and, if the air spaces are not completely collapsed, peripheral. Nevertheless, the two processes remain essentially separate, and it is important to distinguish between them wherever possible.

\section{Group III: Miscellaneous}

Membranous structures were seen in a further eight cases. In a number they were of sparse distribution, were poorly formed, or occurred in babies who had survived for several days and in whom extensive fresh pneumonia made interpretation difficult. Two are of interest in that membranes were formed in the course of a pneumonia obviously acquired after birth; the changes, illustrated in the case presented below, recall those described by Farber and Wilson (1932) in older children with streptococcal lobular pneumonia.

Case 25. Premature labour began spontaneously in a negress, para 10 , and a female child was born who cried well soon after birth. The maturity seemed greater than that given by the mother's history ( 28 weeks; weight $1.63 \mathrm{~kg}$.; crown-heel length $43 \mathrm{~cm}$.). At the end of the second day respiratory distress was noted,

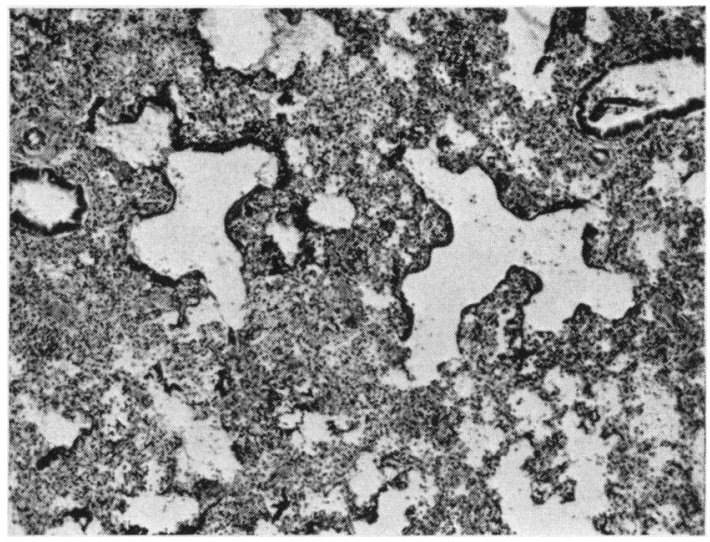

FIG. 9.-Case 25: membrane formation in acquired pneumococcal pneumonia. (Picro-Mallory $\times 48$.)

and in spite of treatment the child died at 58 hours. At autopsy, there were areas of consolidation and haemorrhage in the right lower and middle lobes with surrounding oedema, although elsewhere the lungs were aerated.

Histological examination of the consolidated areas showed dense inflammatory exudate, with large numbers of polymorphonuclear leucocytes, coarse strands of fibrin, and haemorrhage. Many diplococci were present, some intracellular, and these were gram and P.A.S. positive; culture gave a pure heavy growth of Streptococcus pneumoniae. No aspirated material was seen. Brightly eosinophil membranes (Figs. 9 and 10) were seen lining the alveolar ducts at the margins of the larger areas of consolidation and throughout the smaller ones, but were not found elsewhere. The membranes, unlike most of those in Group I and II stained strongly as fibrin with phosphotungstic-acid haematoxylin and the picro-Mallory method. In the other lobes the tissue was aerated.

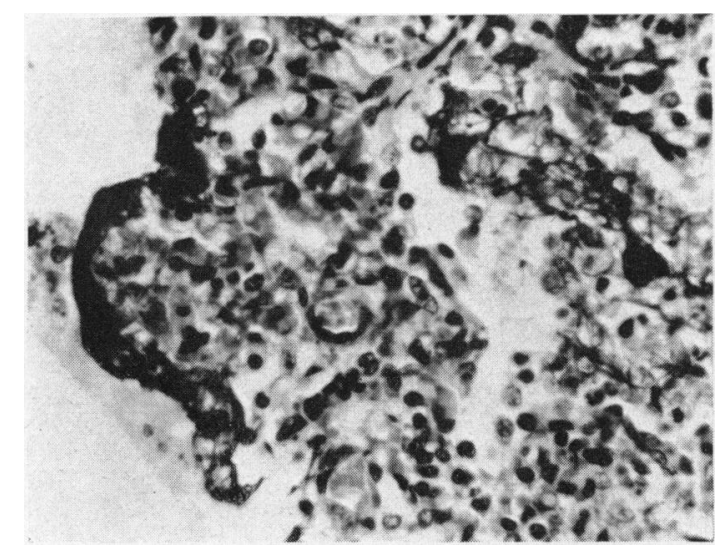

Fig. 10.-Case 25 : the membranes stain strongly as fibrin and contain coarse strands resembling those seen in the exudate (right). (PicroMallory $\times$ 254.) 


\section{Discussion}

The formation of membranes in the course of pneumonia of newborn babies has been described.

In one group of cases the inflammation was localized and associated with aspiration of meconium or similar material, in another it was diffuse, without evidence of such aspiration, but presumably also of prenatal origin, and in a third it was acquired after birth. The membranes can usually be differentiated by their structure from the hyaline membranes that occur with respiratory distress, although this is not always possible; in the absence of such structural features their uneven distribution and association with inflammation may allow distinction to be made. As in other respiratory diseases of the newborn it is important to examine adequate samples of lung tissue.

Information about the babies in Groups I and II is given in the Tables. It will be noted that over one-third of the babies in Groups I and II were mature, by the accepted convention of birth weight. Primary hyaline membranes are uncommon in such babies, unless there is maternal diabetes mellitus and this was not the case here. Also, in Group II most deaths occurred in the first day, and in a number in the first few hours after birth, when formed primary hyaline membranes are rare; it is possible that some of the cases dying within one to two hours of birth and reported as having hyaline membranes are of this type, and that this is the explanation of the rare cases, such as that recorded by Morison (1952), in which membranes are seen in stillbirths after attempted resuscitation. Most babies with primary hyaline membranes die within two days after birth, and those that survive longer usually die as a result of complications; it is likely that the fresh membranes seen in babies of greater age arise during an acquired pneumonia, and that some of these are the result, as may be similar structures in the adult, of the aspiration of irritant material such as gastric content. A pneumonic pathogenesis should be considered whenever primary hyaline membranes are diagnosed, particularly in the lungs of mature babies, of those dying within a few hours of birth, or of those surviving for more than two or three days.

These membranes are merely incidental formations in the course of an inflammatory reaction in the lung, and it is not likely that they cause in themselves any additional disturbance of respiratory function; their importance indeed lies in their possible con- fusion with primary hyaline membranes. The significance of the latter is still uncertain, although a fuller understanding of their origin would contribute greatly to our knowledge of the changes occurring at birth in both the respiratory and cardiovascular systems; and it is important to exclude cases with pneumonic membranes from the further statistical or other investigations of this problem.

\section{Summary}

The hyaline membranes found in the lungs of newborn babies have been shown to consist essentially of fibrin, so that they do not differ in their nature from those found in older patients. In the latter membranes may arise in the course of a number of different pathological processes, and the possibility that this is so in the newborn is considered. Cases are presented in which membranes have formed in the lungs of the newborn as a result of pneumonia, in one group with accompanying aspiration of meconium or other material, in a second without evidence of aspiration but also intrapartum in origin, and in a third acquired after birth. The importance of such membranes lies in the possibility of their confusion with 'primary' hyaline membranes that arise in association with respiratory distress, particularly in mature babies, in those who have died within two or three hours of birth, or those who have survived for more than two days after birth.

My thanks are due to Professor A. C. P. Campbell for his advice on the preparation of this paper, to Professor W. I. C. Morris in whose department the work reported was performed, and to Dr. F. A. Langley for allowing me access to the post-mortem material. Some of the observations are presented in a thesis accepted for the degree of Doctor of Medicine by the University of London.

\section{REFERENCES}

Emery, J. L. (1956). Interstitial emphysema, pneumothorax, and 'air-block' in the newborn. Lancet, 1, 405.

Farber, S. and Wilson, J. L. (1932). The hyaline membrane in the lungs. I. A descriptive study. Arch. Path. (Chicago), 14, 437.

Gitlin, D. and Craig, J. M. (1956). The nature of the hyaline membrane in asphyxia of the newborn. Pediatrics, 17, 64.

Gruenwald, P. (1053). Pulmonary hyaline membrane. In Report of 5 th $M$. and $R$. Pediatric Research Conference.

(1958). The significance of pulmonary hyaline membranes in newborn infants. J. Amer. med. Ass., 166, 621.

Hoccheim, K. (1903). Úber einige Befunde in den Lungen von Neugeboren und die Beziehung derselben zur Aspiration von Fruchtwasser. In Pathologische-Anatomische Arbeiten: Festschrift für Johannes Orth, p. 421. August Hirschwald, Berlin. Langley, F. A. and Smith, J. A. McC. (1959). Perinatal pneumonia. A retrospective study. J. Obstet. Gynaec. Brit. Emp., 66, 12.

Morison, J. E. (1952). Foetal and Neonatal Pathology, p. 141. Butterworth, London.

Potter, E. L. (1952). Pathology of the Fetus and the Newborn, p. 249. The Year Book Publishers, Chicago, Illinois.

Steinharter, R. H. (1937). Die Bildung von hyalinen Membranen in pneumonischen Lungen. Beitr. path. Anat., 99, 148. 